\title{
Diagnosis of Water Tree Aging in XLPE Cable by the Loss Current Harmonic Component Under Variable Frequency Power
}

\author{
Chen Jie ${ }^{1}$, , Li Hongze ${ }^{2}$, Zhou Li ${ }^{1}$, Hu Libin ${ }^{1}$, Li Chenying ${ }^{1}$, Cao Jingying ${ }^{1}$ \\ ${ }^{1}$ State Grid Jiangsu Electric Power Research Institute, Nanjing, China \\ ${ }^{2}$ State Grid Jiangsu Electric Power Company, Nanjing, China
}

Email address:

15105161377@163.com (Chen Jie)

To cite this article:

Chen Jie, Li Hongze, Zhou Li, Hu Libin, Li Chenying, Cao Jingying. Diagnosis of Water Tree Aging in XLPE Cable by the Loss Current Harmonic Component Under Variable Frequency Power. Journal of Electrical and Electronic Engineering. Vol. 3, No. 6, 2015 , pp. $208-214$. doi: $10.11648 /$ j.jeee. 20150306.16

\begin{abstract}
Water treeing is one of the main aging in XLPE cable insulation, which has the direct effect on the reliability of cable long-term operation. The diagnosis of water tree aging is a premise to ensure the safe operation of cables. The water treed XLPE insulation shows a nonlinear conductivity characteristic, which leads to a harmonic component in the corresponding lose current under the standard sinusoidal voltage. So the loss current harmonic component method can be an effective diagnosis of water tree aging. The loss current measurement system based on the high voltage current comparator bridge is used in this paper, which is designed by Harbin University of Science and Technology and Jiangsu Electric Power Company Research Institute. The feasibility of the application of variable frequency series resonant power source in the loss current measurement, which is aimed to diagnose the water treeing in XLPE insulation, is studied in the laboratory and field test. The results show that the output voltage waveform of the variable frequency series resonant power source is quite close to the standard sinusoidal voltage, although there are some high frequency sharp peaks. So the variable frequency series resonant power source can be used as the high voltage test power supply in the loss current harmonic component measurement system. The loss current harmonic component has power frequency interference during the field test, but this can be solved by differential frequency principle. The microscopic observation of water tree structures during the anatomy of the cable not only indicates the effectiveness of the results and diagnosis during the field test, but also proves the feasibility of the application of variable frequency series resonant power source in the loss current measurement. The existence and degree of the water tree can be estimated according to the test results, which can be a strong basis of the standardization of water tree aging diagnosis. Furthermore, the expensive standard sinusoidal wave generator and linear power generator is replaced by the variable frequency series resonant power source, which reduces the cost and weight of the testing system.
\end{abstract}

Keywords: Loss Current Harmonic Component Test System, Variable Frequency Resonant Power Source, Water Tree Aging Diagnosis, Field Test

\section{Introduction}

XLPE power cable is widely used due to its large transmission capacity, good insulation performance, and easy installation and maintenance. But the unplanned shutdown accidents of cable increase because of aging. And the water tree aging is one of the main aging in XLPE cable insulation, which has the direct effect on the reliability of cable long-term operation[1]. When the insulation material is suffered a long-term alternating electric field and humidity, the chemical component and micro structure may be changed, and finally lead to the irreversible degradation, which is called water tree aging. The water tree is a permanent degradation and can grow under a low electric field and a very few humidity. The diagnosis of water tree aging is essential to insure the safety of the cable line[2]. Therefore, the study of water tree aging diagnosis in XLPE insulation is always a hot research topic[3, 4].

The vehicular loss current harmonic component test system was developed in Japan, and the system was applied in 7 high voltage cable lines successfully, which proved the 
feasibility of the test method and formed the corresponding test standard. The output voltage of the system is $0 \sim 20 \mathrm{kV}$ $(50 \mathrm{~Hz})$, and the maximum load is $1 \mu \mathrm{F}$. In the test system, a standard sinusoidal voltage is first produced by the signal generator, and then enlarged by the linear power amplifier to become a high power voltage signal which can drive the experimental transformer. Finally, the high voltage standard sinusoidal wave is generated by the experimental transformer, which is the voltage source for tests[5, 6]. However, the linear power amplifier is very expensive, and the equipment weight is 4 tons. These are harmful to the universal application of the test system. So, the feasibility of the application of variable frequency series resonant power source in the loss current harmonic component measurement system is studied in this paper.

\section{Testing Principle and Equipment}

\subsection{Loss Current Harmonic Component Testing Principle}

When the insulation structure is describe by the equivalent circuit, the loss current has the same phase with the applied voltage, and the capacitance current is 90 degrees ahead of the applied voltage. The relationship among the loss current, the capacitance current and the total current is shown in Figure 1.

The loss current harmonic component is the loss current harmonic of each frequency after the Fourier transform. The conductivity of the non-aging XLPE cable insulation is linear, so the loss current is not distorted and has no harmonic component when the standard sinusoidal voltage is applied, and the dissipation factor is small. But when the XLPE cable is water treed, the conductivity is nonlinear because of water and the low molecular degradation products, so the loss current is distorted and the harmonic component is detected.

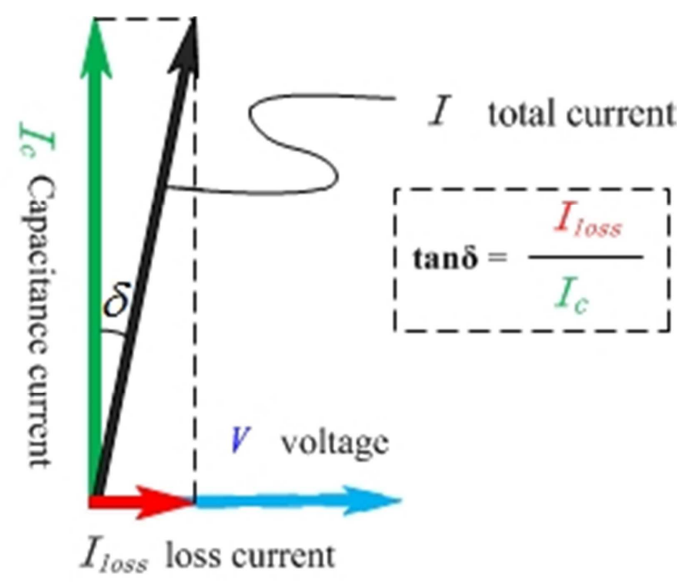

Figure 1. Vector relationship among the loss current, the capacitance current, the total current and the applied voltage.

The loss current harmonic component test results of water treed XLPE samples with varying degrees in the laboratory are shown in Figure 2.

Studies both at home and abroad show that: 1) when the dissipation factor increases and the loss current has no harmonic component, the dissipation factor has a certain relationship with the thermal aging degree. 2) when the dissipation factor increases and the loss current has a third harmonic component, the third harmonic component is the indication of water treeing, the corresponding amplitude is related to the quantity of water tree (the area of water trees along the cable length direction), and the phase is related to the length of water tree (the depth of water tree in the cable radial direction). Thus the measurement of the loss current harmonic component can be used to diagnose the water treeing degree in XLPE cable insulation.

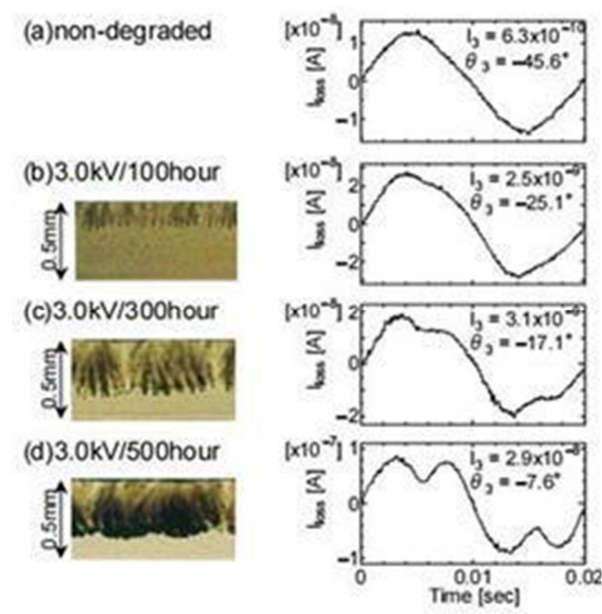

Figure 2. Loss current harmonic component test results of different water tree aging XLPE sample.

\subsection{Loss Current Harmonic Component Testing Equipment}

The loss current harmonic component testing equipment are mainly composed by the high voltage power system, the high voltage current comparator bridge, the high voltage standard capacitor, the zero current detector, the capacitance voltage divider, the data acquisition and processing circuits, the LCD displaying circuit, the filter and amplifier circuits, the oscilloscope, and the computer[7-10]. The schematic diagram of test equipment is shown in Figure 3.

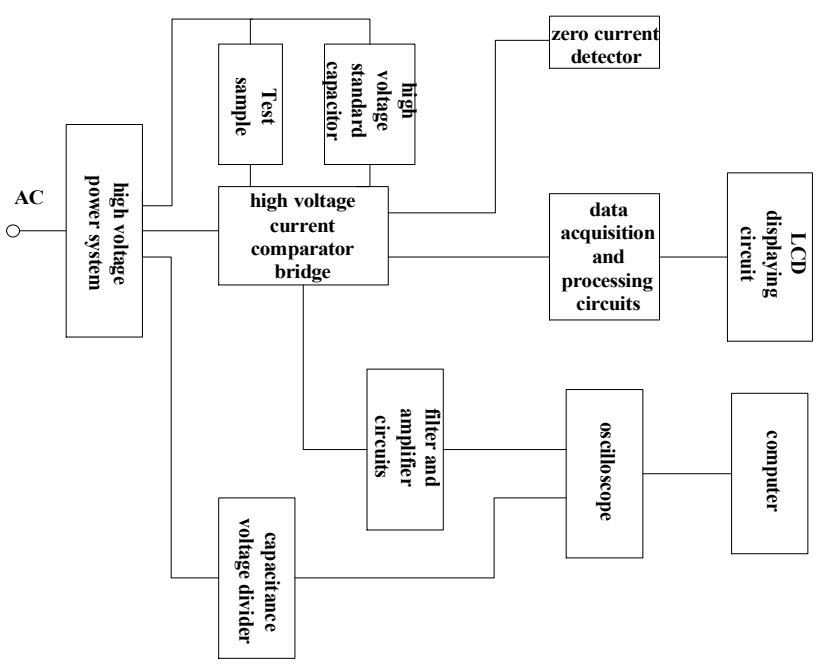

Figure 3. Schematic diagram of the loss current harmonic component test equipment. 
The test system used in this paper is based on the comparison method, and the high voltage current comparator bridge is a core part. The loss current measurement of the test sample is implemented by the electromagnetic induction and ampere turn balance law. The high voltage standard capacitor is the comparison standard, which used to get the loss current information by comparing with the current through the test sample. The zero current detector is the basis of the balance of high voltage current comparator bridge. The output signal is captured and processed by the data acquisition and processing circuits. Then the dielectric loss tangent $(\tan \delta)$, the capacitance, the test voltage and the current through the standard capacitor are displayed by the LCD displaying circuit. The loss current is filtered and amplified by the the filter and amplifier circuits, which is observed with the output voltage signal of power source by the oscilloscope. The loss current harmonic data is obtained and analyzed by the computer.

The connection mode of the test system can be forward or backward connection, which are fit for laboratory and field test separately. In the forward connection, the high testing voltage is supplied by the common high voltage testing transformer, and the loss current is imported to the current comparator from the low voltage side of the sample, which is connected with the proportional coil. The laboratory test for short cable (small capacitance sample) can be carried out by adjusting the proportional coil. In the backward connection, the high voltage power source connected with the testing cable through the current comparator by the coaxial shielded high voltage cable, and the loss current is imported to the current comparator from the high voltage side. In this situation, the current comparator is single-turn cored structure, and the field test for long cable can be carried out.

The loss current testing equipment is not only able to measure the dielectric loss tangent $(\tan \delta)$, the capacitance, the test voltage, the current through the standard capacitor, the loss current and the loss current harmonic component, but also can observe the waveform of the test voltage and the loss current. The adjustable parameters during the test are mainly the test voltage $U_{0}$, the sensitivity $\eta$, the amplification ratio $K_{\mathrm{u}}$ and the resonant frequency $f$.

\section{Feasibility Verifying of the Variable Frequency Series Resonant Power Source}

\subsection{Establishment of the Verification Program}

The following program is established to verify the feasibility of the variable frequency series resonant power source in the diagnosis of water tree aging. First, the test system with the variable frequency series resonant power source is used in the laboratory test to see the feasibility. Then, the test system is used in the field test as the key task to diagnose the cables with water trees. Finally, the above-mentioned cables are sliced to see water trees, which is aimed to confirm the diagnosis results. The completed verification and conclusion are obtained according to the laboratory and field tests.

\subsection{Laboratory Verification Test}

The capacitance of the short cable is very small, so the tested cable needs to be paralleled with compensation capacitors to get a necessary capacitance to satisfy the resonance condition, which makes the variable frequency series resonant equipment work in the required frequency range.

Two compensation capacitors $(4000 \mathrm{pF})$ were paralleled with a new $35 \mathrm{kV}$ XLPE cable for testing. The photo of this laboratory test is shown in Figure 4. The applied alternating test voltages $\mathrm{U} 0$ are $3.4 \mathrm{kV}, 7.5 \mathrm{kV}$, and $10.0 \mathrm{kV}$ in turn, the acquired waveforms of the test voltages, the loss currents and harmonic components are shown in Figure 5. Channel 1 of the oscilloscope is the signal of the test voltage, channel 2 is the signal of the loss current, and the nethermost signal is the harmonic component of loss current after Fourier transform. All the subsequent similar figures are exactly the same and will not be described again.

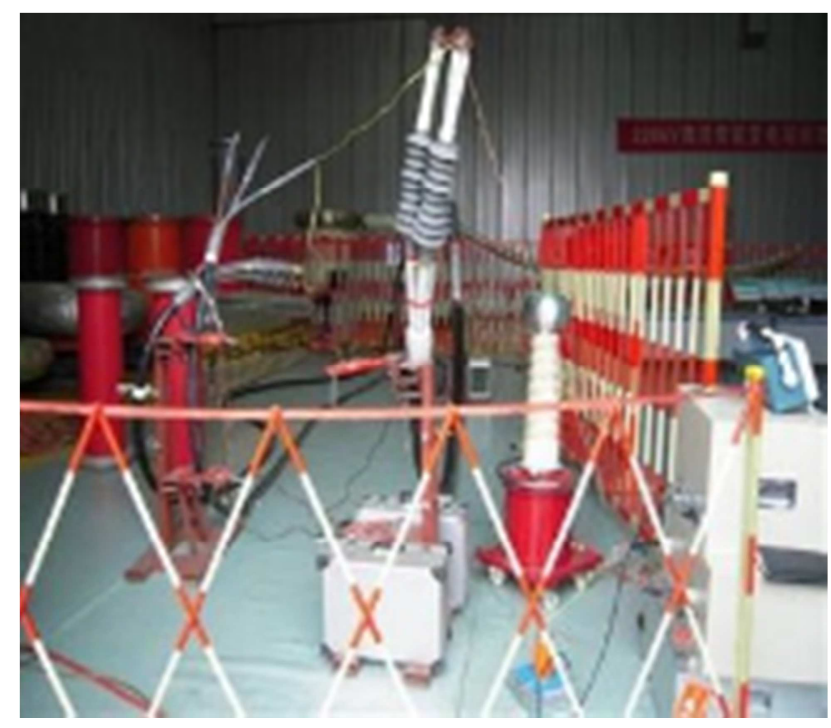

Figure 4. Photo of the laboratory verification test.

The voltage waveform of the variable frequency series resonant power source in Figure 4 is quite close to the standard sinusoidal voltage, although there are some high frequency sharp peaks. The high frequency sharp peaks superimposed on the sinusoidal waveform are produced by the switch off of the power electronic devices in the variable frequency resonant power source, and the frequency range is $\mathrm{kHz} \sim \mathrm{MHz}$, which is much higher than the main test frequency and the frequency of harmonic. As a result, the sharp peaks have no effect on the measurement of the loss current harmonic component. The laboratory test demonstrate the feasibility of the variable frequency series resonant power source preliminarily. 


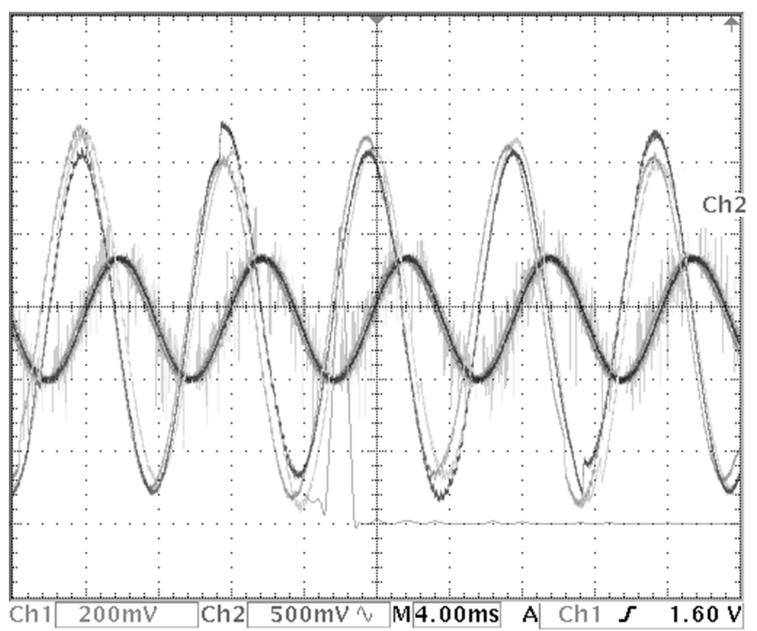

(a) $\mathrm{U} 0=3.4 \mathrm{kV} ; \eta=7 ; \mathrm{Ku}=10000 ; \mathrm{f}=126.47 \mathrm{~Hz}$

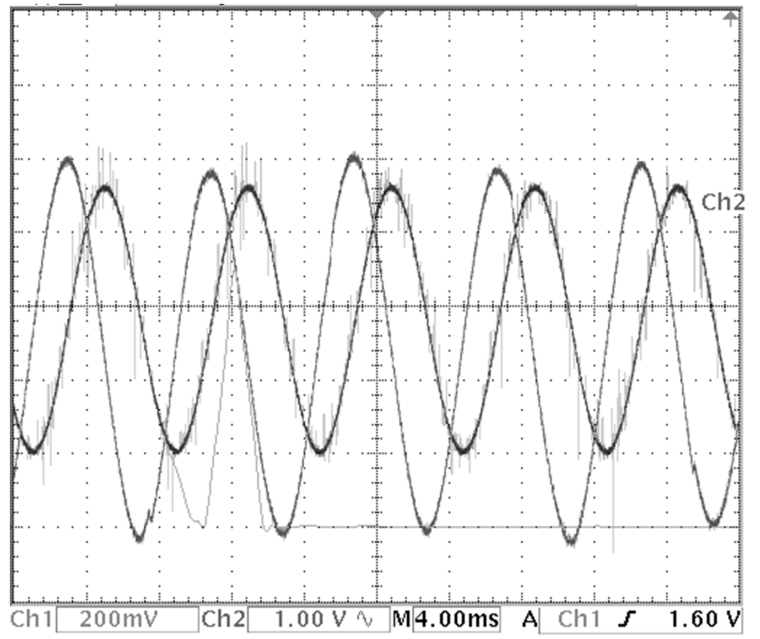

(b) $\mathrm{U} 0=7.5 \mathrm{kV} ; \eta=7 ; \mathrm{Ku}=10000 ; \mathrm{f}=126.43 \mathrm{~Hz}$

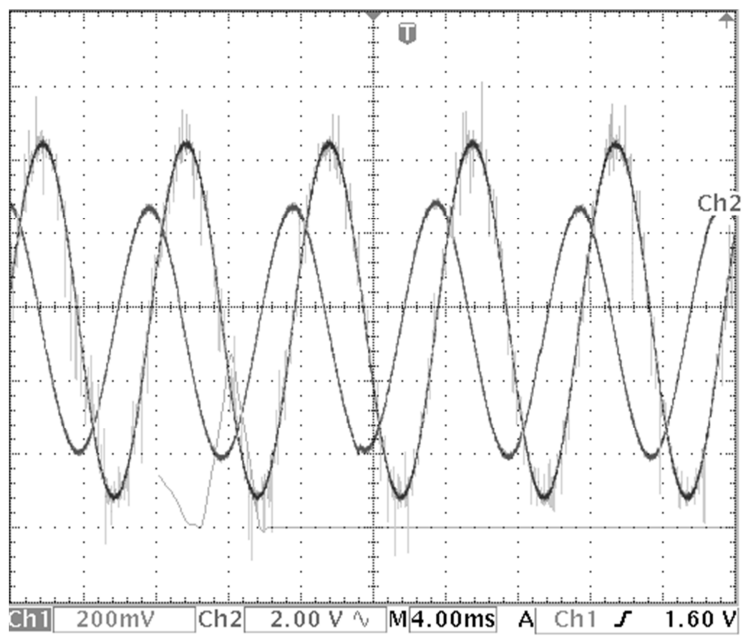

(c) $\mathrm{U} 0=10.0 \mathrm{kV} ; \eta=7 ; \mathrm{Ku}=10000 ; \mathrm{f}=126.43 \mathrm{~Hz}$

Figure 5. Waveforms of the test voltages, the loss currents and harmonic components under different test voltages.

\subsection{Field Verification Test and Analysis}

The field verification tests are conducted in Jiangsu province. 70 cables in distribution grid are tested in the field, and 16 cables have water trees in total, of which 12 cables are slight water tree aging while 4 cables are serious aging. Two typical cable lines are taken for examples: a $35 \mathrm{kV}$ cable line in Zhenjiang is marked as \#1 cable, a $10 \mathrm{kV}$ cable line in Changzhou is marked as \#2 cable. Three phases in the two cable lines are all water treed. The photo of the field test is shown in Figure 6. The test voltage, the amplitude of the third harmonic component and the dielectric loss tangent $(\tan \delta)$ of the two typical cables are listed in Table 1.

The test results of \#1 cable (test voltage $U_{0}$ is $3.5 \mathrm{kV}$ or $8.0 \mathrm{kV}$ ) and $\# 2$ cable (test voltage $U_{0}$ is $8.0 \mathrm{kV}$ or $10.0 \mathrm{kV}$ ) are shown in Figure 7.

It is evident from Figure 7 that the loss current of both cable lines are distorted, and there are obvious third harmonic components in the loss currents.

Table 1. The test voltage, the amplitude of the third harmonic component and the dielectric loss tangent (tand) of the two typical cables.

\begin{tabular}{llllll}
\hline \#1 cable line $\left(\boldsymbol{\eta}=\mathbf{7} ; \boldsymbol{K}_{\boldsymbol{u}}=\mathbf{1 0 0 0 0}\right)$ & \multicolumn{4}{l}{ \#2 cable line $\left(\boldsymbol{\eta}=\mathbf{7} ; \boldsymbol{K}_{\boldsymbol{u}}=\mathbf{1 0 0 0 0}\right)$} \\
\hline $\begin{array}{l}\text { Test } \\
\text { voltage/ } \\
\mathbf{k V}\end{array}$ & $\begin{array}{l}\text { Amplitude } \\
\text { of the third } \\
\text { harmonic } \\
\text { component/ } \\
\mathbf{m V}\end{array}$ & $\begin{array}{l}\text { Tan } \boldsymbol{\delta} \\
\times \mathbf{1 0}\end{array}$ & $\begin{array}{l}\text { Test } \\
\text { voltage/ } \mathbf{k} \\
\mathbf{V}\end{array}$ & $\begin{array}{l}\text { Amplitude } \\
\text { of the third } \\
\text { harmonic } \\
\text { component/ } \\
\mathbf{m V}\end{array}$ & $\begin{array}{l}\text { Tan } \boldsymbol{\delta} \\
\times \mathbf{1 0}^{-4}\end{array}$ \\
\hline 3.5 & 265 & 1.26 & 4.0 & 80 & 3.82 \\
5.0 & 640 & 2.27 & 6.0 & 145 & 5.02 \\
6.5 & 1299 & 3.33 & 8.0 & 1000 & 10.2 \\
8.0 & 2133 & 4.79 & 10.0 & 4100 & 25.1 \\
9.5 & 3700 & 6.60 & - & - & - \\
\hline
\end{tabular}

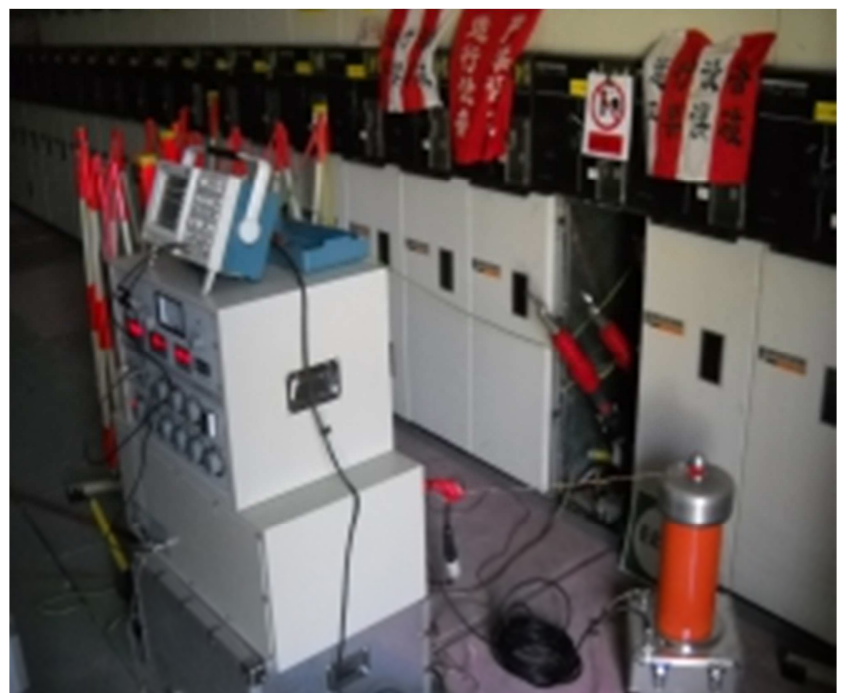

Figure 6. Photo of the field verification test.

Fourier transform results of the tested loss currents under different test voltage are compared in Figure 8. It is clear that the loss currents have the apparent third harmonic components, which means the tested cables are apparently water treed. 


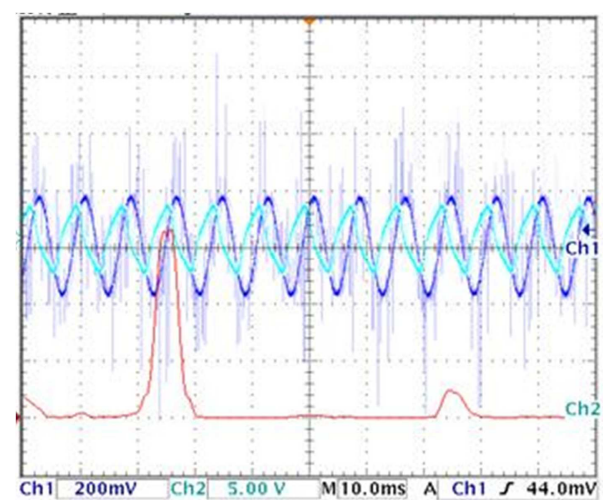

(a) \#1 cable $\mathrm{U} 0=3.5 \mathrm{kV}, \mathrm{f}=125.04 \mathrm{~Hz}$

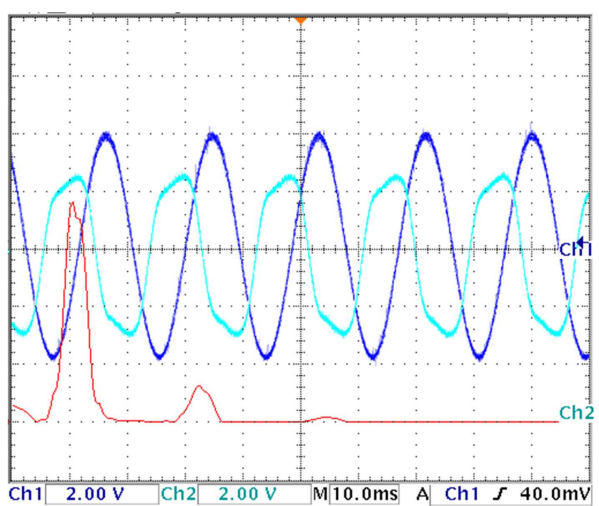

(c) \#2 cable $\mathrm{U} 0=4.0 \mathrm{kV}, \mathrm{f}=54.17 \mathrm{~Hz}$

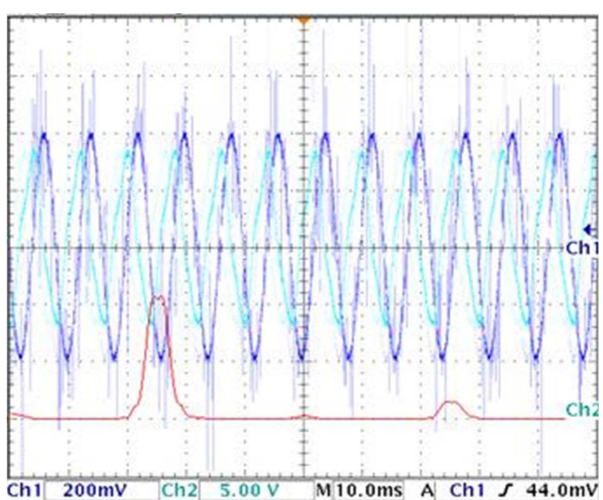

(b) \#1 cable $\mathrm{U} 0=8.0 \mathrm{kV}, \mathrm{f}=125.07 \mathrm{~Hz}$

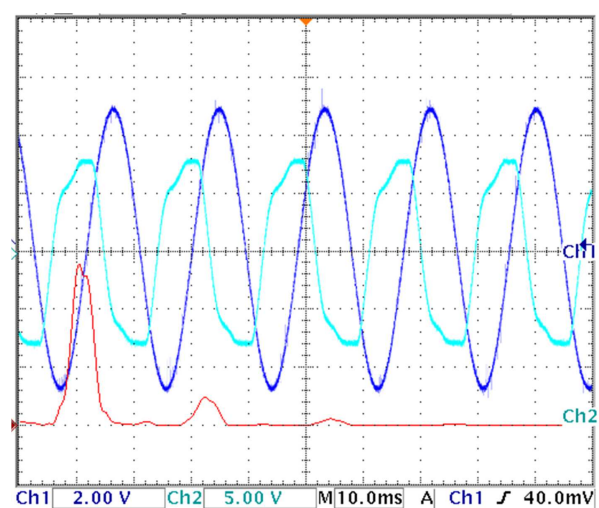

(d) \#2 cable

$\mathrm{U} 0=8.0 \mathrm{kV}, \mathrm{f}=54.20 \mathrm{~Hz}$

Figure 7. Test results of \#1 cable and \#2 cable.

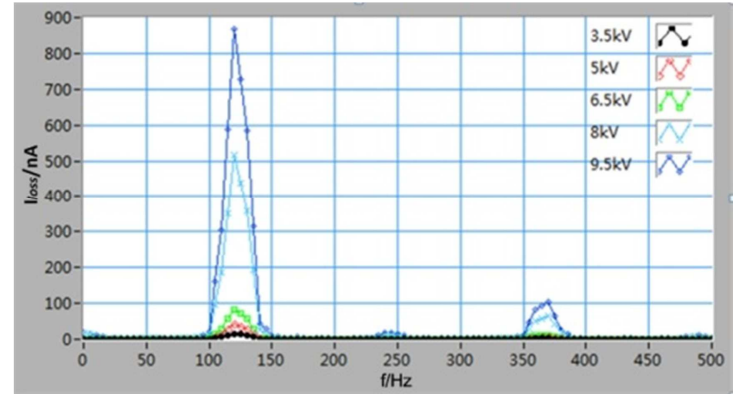

(a) \#1 cable line

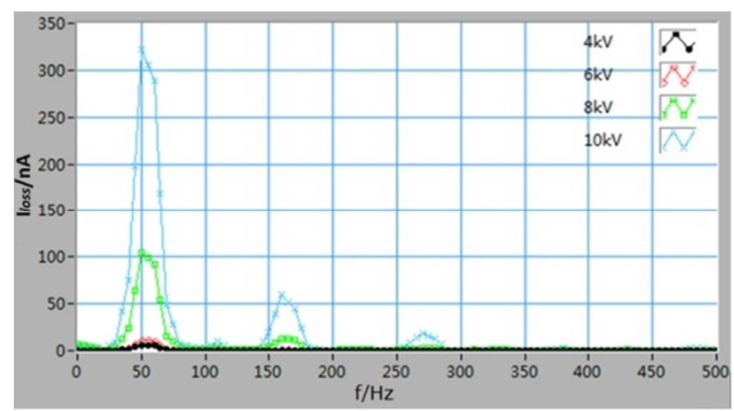

(b) \#2 cable line

Figure 8. Fourier transform results of the tested loss currents under different test voltage.

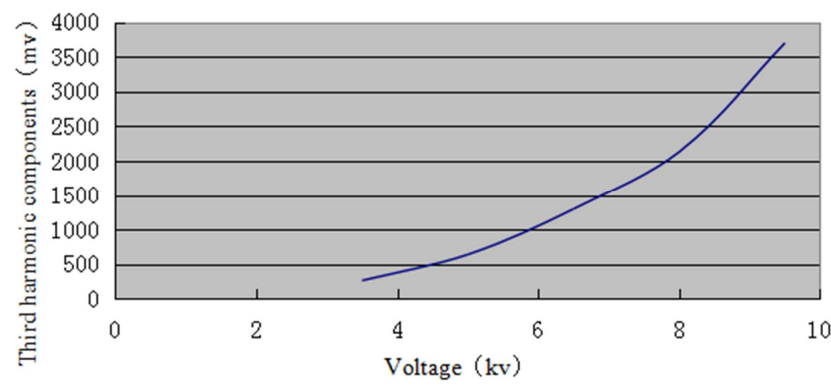

(a) \#1 cable line

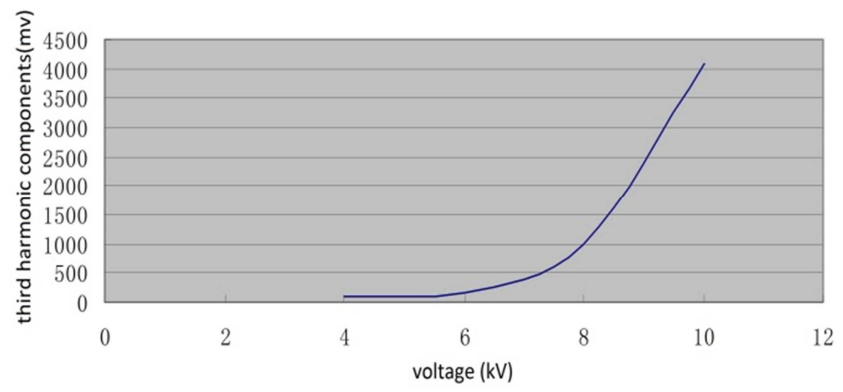

(b) \#2 cable line

Figure 9. Varying laws of the third harmonic components with the test voltage. 
The third harmonic components change with the test voltage, and the varying laws are shown in Figure 9. It is indicated that the conductivity of the insulation material is nonlinear. The nonlinear relationship between the third harmonic components change and the test voltage also proves the existence of water tree aging in insulation.

The changes of the dielectric loss tangent $(\tan \delta)$ with the test voltage are given in Figure 10, which also show the nonlinear relationship. This is another evidence of aging in cables. It can be seen that the largest $\tan \delta$ of \#1 cable is $6.6 \%$ and of $\# 2$ cable is $25.1 \%$, which indicates that \#1 cable is serious aging and \#2 cable is slight aging.

\subsection{Verification Observation of Water Tree in Cables}

The results of the laboratory and field tests are verified further by the variable frequency withstand voltage tests of the 16 cables with water trees. All the 12 cables with slight water tree aging passed the withstand voltage tests, meanwhile all the 4 cables with serious aging were breakdown. The breakdown cables were sliced and observed by China Electric Power Research Institute (CEPRI) and Harbin University of Science and Technology (HUST). Figure 11 is the optical microscope observation of water trees in the breakdown cables.

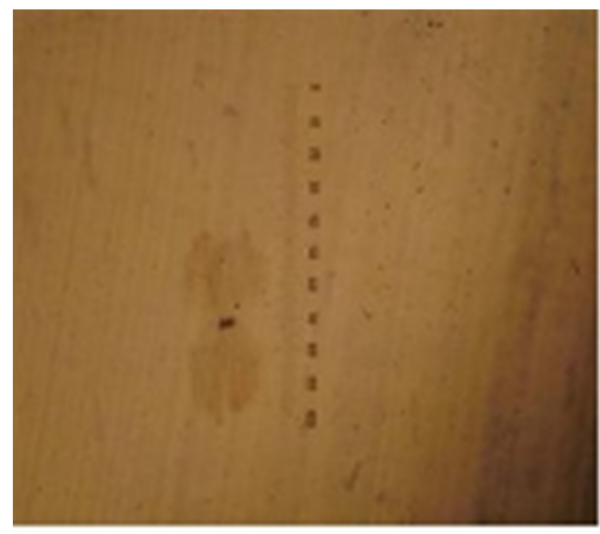

(a) observed water tree by CEPRI

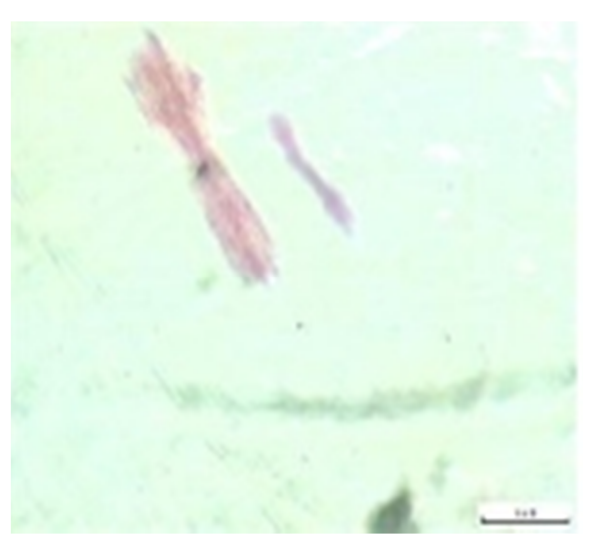

(c) observed water tree by HUST

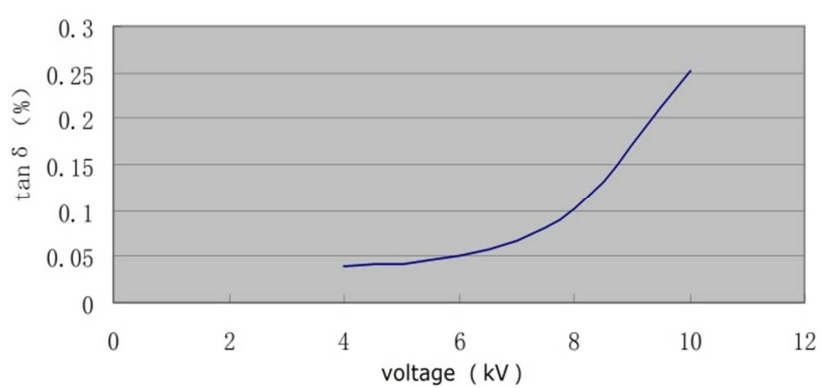

(a) \#1 cable line

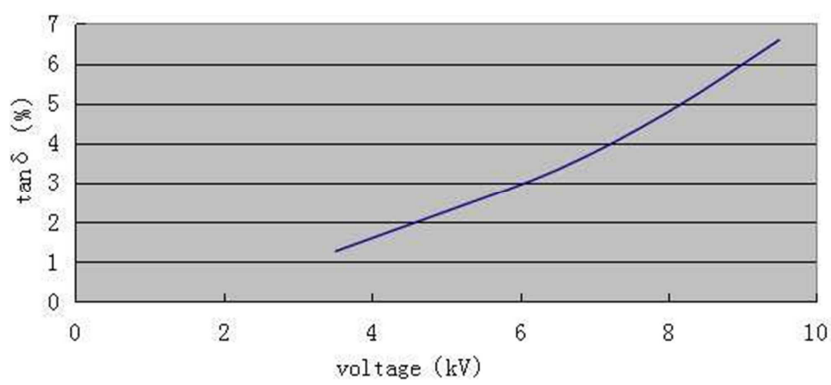

(b) \#2 cable line

Figure 10. Varying laws of the dielectric loss tangent with the test voltage.

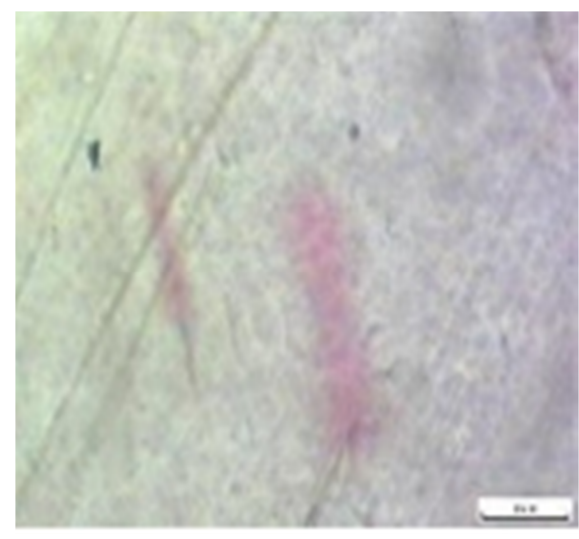

(b) observed water tree by HUST

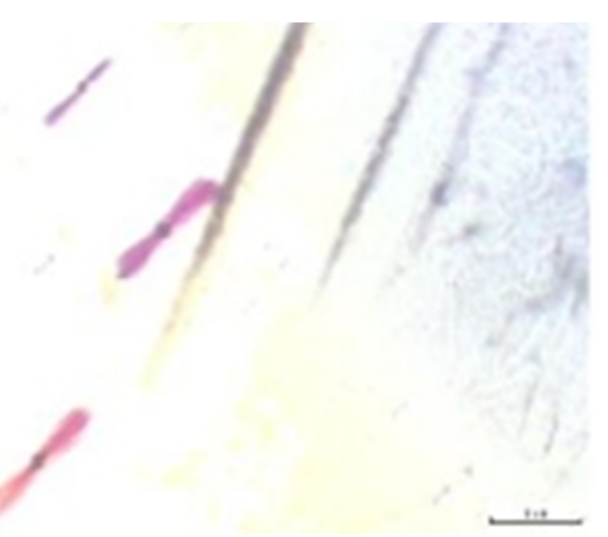

(d) observed water tree by HUST

Figure 11. Optical microscope observation of water trees in the breakdown cables.

The butterfly water trees are observed both by CEPRI and HUST. The area of water tree appears larger in the results of
CEPRI, but the number of water tree is more in the results of HUST. Anyway, the structure observation of water tree have 
confirmed the serious water aging in cables, which prove the effectiveness of the results and diagnosis during the field test and the feasibility of the application of variable frequency series resonant power source in the loss current measurement.

\section{Conclusion}

The voltage waveform of the variable frequency series resonant power source is quite close to the standard sinusoidal voltage, although there are some high frequency sharp peaks. The variable frequency series resonant power source is feasible to be the high voltage for the loss current harmonic component measurement.

The loss current harmonic component has power frequency interference during the field test, but this can be solved by differential frequency principle.

The structure observation of water tree have confirmed the serious water aging in cables, which prove the effectiveness of the results and diagnosis during the field test and the feasibility of the application of variable frequency series resonant power source in the loss current measurement.

The existence and degree of the water tree can be estimated according to the test results, which can be a strong basis of the standardization of water tree aging diagnosis.

The expensive standard sinusoidal wave generator and linear power generator can be replaced by the variable frequency series resonant power source, which will reduce the cost and weight of the testing system.

\section{References}

[1] Zheng Xiaoquan, Wang Jinfeng and Li Yanxiong. Transformation of Electrical Tree from Water Tree Degradation in XLPE [J]. Proceedings of the CSEE, 2013, 36(22): 166-174.
[2] KENICHI HIROTSU. Development of Hot-line Diagnosis Method for XLPE Cables by Measurement of Harmonics Current[C]. Proceedings of 1994 International Joint Conference: 26th Symposium on Electrical Insulation Materials, Osaka, Japan, 1994: 455 458.

[3] Shen Feifei, Zhang Jianliang, Lv Peiqiang and et al. Early Feature Evaluation of Distribution Network Cable Insulation Water Tree Based on Loss Current Harmonic Component [J]. East China Electric Power, 2013, 41(12): 18-24.

[4] Gao Zhen. Measurement of the loss current harmonic component in cable insulation under variable frequency power [D]. Harbin University of Science and Technology, 2012.

[5] Y. YAGI, H. TANAKA, H. KIMURA. Study on Diagnostic Method for XLPE Cable by Harmonics in Loss Current [J]. Electrical Insulation and Dielectric Phenomena, 1998: 653 $\sim 656$.

[6] TANAKAATSUSHI, YAGIYUKIHIRO, TANAKA HIDEO. On-site Diagnostic Method for Water Treed XLPE Cable by Harmonics in AC Loss Current[J]. Electrical Insulation New News in Asia, 2003, (10): 29 30.

[7] E. MOREAU, C. MAYOUX and C. LAURENT. The Structure Characteristics of Water Trees in Power Cables and Laboratory Specimens [J]. IEEE Trans. on EI, 1993, (1): 54 64.

[8] Han Jiajia. Design of the loss current harmonic component measurement system based on FPGA and the current comparator bridge [D]. Harbin University of Science and Technology, 2013.

[9] Zhao Q, Amagasaki M, Iida M. An automatic FPGA design and implementation framework[C]. Field Programmable Logic and Applications (FPL), 2013 23rd International Conference on. IEEE, 2013: 1-4.

[10] Xinlao Wei, Bo Zhu, Bing Pang, Song Wang, Ruihai Li, "On-line Insulation Monitoring Method for Long Distance Three-Phase Power Cable," Proceedings of the Chinese Electrical Engineering Science, vol.35 No.8, Apr. 20, 2015. 